\title{
LIÇÕES DE REFORMAS DA GESTÃO EDUCACIONAL Brasil, EUA e Grã-Bretanha
}

ANDRÉ Borges

\begin{abstract}
Resumo: O artigo discute a recente onda de reformas da gestão educacional no Brasil e nos países desenvolvidos de língua inglesa que visam ampliar a participação comunitária na administração da escola. A partir de várias análises, argumenta-se que tais reformas têm sido pouco eficazes na promoção do empowerment de pais e alunos.

Palavras-chave: descentralização da educação; reformas; conselhos escolares.
\end{abstract}

Abstract: This article deals with the recent wave of reforms on the educational administration in Brazil and in the English-speaking developed countries that intend to expand the community participation in the school administration. Based on several analyses, it argues that such reforms are not effective enough to empower students and their parents.

Key words: education decentralization; reforms; school councils.

$\mathrm{N}$ as últimas duas décadas tem se observado um movimento de dimensões mundiais rumo a padrões descentralizados de gestão dos sistemas educacionais. Reformas implementadas tanto nos países em desenvolvimento como nos desenvolvidos vêm buscando repassar poderes administrativos e financeiros para as escolas e promover o empowerment da comunidade escolar por meio de estruturas de gestão colegiadas e representativas. Em certa medida, a difusão das reformas descentralizadoras refletiu o descontentamento generalizado com os modelos burocráticos e centralizados de gestão das políticas sociais associados ao Estadoprovidência europeu e ao desenvolvimentismo no Terceiro Mundo, razão para sua rápida aceitação nos mais variados contextos.

Na medida em que a descentralização e o "empoderamento" (empowerment) da comunidade escolar têm sido advogados por grupos de variados matizes ideológi$\cos$, indo da direita neoconservadora à esquerda socialista e social-democrata, os argumentos em torno destas pro- postas têm sido com freqüência díspares. Entretanto, em que pesem as divergências ideológicas entre os defensores das reformas descentralizantes, é possível identificar um claro ponto de convergência. Trata-se da crença de que é necessário desestatizar a escola pública e submetê-la ao controle da comunidade, reduzindo, inversamente, o poder dos vários agentes do Estado - políticos, administradores e professores - sobre a instituição educacional. De fato, tanto as perspectivas de esquerda quanto de direita parecem apostar na "libertação" da sociedade civil das amarras estatais (BECKMAN, 1993) como o remédio mais adequado para os males do centralismo burocrático.

A partir de algumas análises desenvolvidas sobre o tema, o artigo busca demonstrar que as políticas de descentralização e reforma da governança escolar são com freqüência ineficazes na promoção do empoderamento dos grupos menos favorecidos e excluídos do processo decisório no interior das escolas, não obstante as expectativas criadas em torno dessas políticas. Diante dessa constatação, o texto procura examinar algumas das possíveis razões 
para as limitações observadas no processo de descentralização da educação.

Fazendo uma crítica aos argumentos da literatura especializada em torno das "falhas" do empoderamento, o artigo observa como a política da descentralização reflete, no plano macro, uma disputa intra-estatal pelo poder, na medida em que professores, administradores educacionais e políticos eleitos buscam manter ou mesmo melhorar suas posições, em detrimento dos grupos que se espera "empoderar". No plano da micropolítica, de forma complementar, a tentativa de reordenar as relações de poder no interior da escola esbarra na lógica de disciplina e autoridade que caracteriza a instituição educacional, lógica esta personificada no professor.

Para desenvolver tais pontos, o artigo traça um breve panorama de variantes de empoderamento na educação e dos argumentos em torno destas. Em seguida, apresenta algumas evidências recolhidas em pesquisas realizadas na Grã-Bretanha e nos EUA. Por fim, são discutidas algumas experiências de reforma realizadas no Brasil, no âmbito dos Estados e municípios. $\mathrm{O}$ artigo centra a análise em duas políticas de empoderamento da comunidade escolar: os conselhos escolares e a eleição de diretores de escola.

\section{EMPODERAMENTOE GESTÃO EDUCACIONAL}

\section{Variedades de Empoderamento na Educação}

O conceito de empoderamento vem associado na literatura à criação de estruturas independentes e autogeridas. De modo geral, o termo pode ser definido como a capacidade de determinado grupo ou indivíduo controlar seu próprio ambiente, envolvendo não apenas o acesso a recursos materiais e o controle sobre as decisões relevantes, mas também uma disposição psicológica compatível com o autogoverno (HANDLER, 1996). O empoderamento vem associado à descentralização política, na medida em que esta envolve a transferência de poder decisório a grupos ou indivíduos previamente sub-representados ou desfavorecidos e à criação de unidades administrativas relativamente independentes. A descentralização de caráter administrativo, em contraste, é mais limitada, pois tende a levar apenas à desconcentração de poder dentro das estruturas burocráticas existentes (por exemplo com a transferência de tarefas administrativas do Ministério da Educação para as escolas), não levando ao empoderamento dos grupos previamente excluídos do processo decisório (SAMOFF, 1990; SUNDAR, 2001).
O conceito de "empoderamento", assim como "democracia" ou "poder", é essencialmente contestável, revelando uma interminável disputa teórica em torno da sua definição. Nesse sentido, a depender da orientação teórica ou ideológica do analista, são enfatizados determinados aspectos ou modalidades de "empoderamento". No que tange às reformas da educação, o debate em torno do conceito reflete uma disputa mais ampla sobre o controle das escolas e do processo educacional, que por sua vez se relaciona a distintos modelos de organização do Estado e da sociedade.

$\mathrm{Na}$ tradição das pedagogias progressistas, o empoderamento vem associado à tomada de consciência, à mobilização coletiva e à radicalização da democracia. O mais importante nestas perspectivas é garantir a mudança efetiva nas estruturas de poder no interior das escolas, quebrando os padrões hierárquicos e autoritários da relação educadoreducando (FREIRE, 1972; GANDIM; APPLE, 2002; FISCHMAN; MCLAREN, 2000). De modo geral, tais perspectivas se amparam em variadas versões do "socialismo democrático" - anarquista, sindicalista ou cristão - para defender o empoderamento da comunidade escolar e a revisão dos métodos tradicionais de ensino (LAUGLO, 1995).

A perspectiva do liberalismo econômico, por sua vez, assume que as escolas devem tornar-se mais accountable perante os pais e alunos com a introdução de mecanismos de mercado. Do ponto de vista dos liberais, o sistema de "controle democrático" da escola pública é ineficaz, na medida em que transforma as escolas num espaço de luta política entre vários grupos - sindicatos de professores, políticos e administradores educacionais - cujos interesses não necessariamente refletem as preferências dos "usuários da escola", i.e., pais e alunos (CHUBB; MOE, 1988). Na formulação original de Milton Friedman (1965), se os pais e os estudantes pudessem escolher entre escolas públicas e privadas usando "cupons" (vouchers) financiados por recursos governamentais, a competição entre as escolas pelos "consumidores" as forçaria a refletir as preferências individuais.

Os defensores da criação de mecanismos de escolha no sistema educacional (school choice) argumentam que a ampliação do poder de escolha reduz as desigualdades educacionais, permitindo que os estudantes pobres tenham acesso à educação de maior qualidade, isto é, à educação privada (WORLD BANK, 1995a). Além disso, argumentase que o empoderamento dos usuários da escola via mercado minimizará a segregação em linhas classistas ou raciais (CLUNE; WITTE, 1990). ${ }^{1}$ 
Um último e importante modelo de empoderamento, sobre o qual este artigo se debruça mais detalhadamente, envolve a transferência da autoridade dos professores e burocratas para pais, estudantes e outros representantes da comunidade escolar. Esta modalidade envolve a transferência do poder decisório para conselhos escolares compostos por representantes da comunidade e a eleição direta dos administradores educacionais. A introdução de estruturas colegiadas e democráticas é normalmente complementada com o reforço da "autonomia" da escola, por meio da transferência direta de recursos a serem aplicados pelos conselhos. ${ }^{2} \mathrm{O}$ argumento para esse tipo de empoderamento é geralmente construído a partir da crítica antiburocrática e antiprofissões ao Estado em suas variantes de esquerda e de direita.

$\mathrm{Na}$ visão da esquerda, a criação de estruturas colegiadas e democráticas no interior da escola deve levar necessariamente à radicalização da democracia e ao resgate das formas de vida comunitárias solapadas por formas de controle burocrático ou de mercado (FISCHMAN; MCLAREN, 2000). No caso brasileiro, vale dizer, a defesa da "democratização" da escola pela esquerda confundiu-se com a crítica ao Estado autoritário e seu modelo de gestão de políticas sociais privatista e centralizador (CUNHA, 1991; RODRIGUES, 1997). É assim que, dada a inexistência prévia de um modelo universalista de provisão de serviços sociais, a crítica ao estatismo centrou-se no combate ao clientelismo, ao corporativismo e à corrupção, mais do que à burocratização stricto sensu.

Na perspectiva da direita neoconservadora, particularmente nos países anglo-americanos, a defesa da escola "autogerida" ocorreu em termos dos possíveis impactos sobre a eficiência administrativa, redução de custos e maior resposta dos professores e administradores aos usuários da escola (LEVACIC, 1995; WHITTY; HALPIN; POWER, 1998). Os governos da Nova Direita que adotaram este modelo buscavam introduzir incentivos de mercado e reduzir o poder dos professores e seus sindicatos, ao mesmo tempo em que restabeleciam controles centralizados sobre os currículos (WHITTY; POWER, 2000; RAAB, 2000). ${ }^{3}$

\section{Conferindo Poder à Comunidade Escolar: Diversidade e Consenso}

De modo geral, as reformas contemporâneas da educação em vários países têm sido caracterizadas pela substituição dos modelos de controle profissional e burocrático tradicionais por mecanismos de quase-mercado e pela transferência do poder decisório para as comunidades escolares. Na América Latina, as agências internacionais de financiamento tiveram papel importante na difusão do novo consenso, na esteira dos seus programas de "ajustamento estrutural" (ARNOVE, 1997; TOMMASI et al., 1998). Na Grã-Bretanha, Austrália, Nova Zelândia e nos EUA, foram principalmente os partidos conservadores e os think-tanks associados a estes os responsáveis pela difusão das propostas (WHITTY; POWER, 2000). É assim que tanto nos países desenvolvidos de língua inglesa quanto nos países latino-americanos os quase-mercados e o empoderamento da comunidade tornaram-se tendências hegemônicas na recente onda de reformas da governança escolar (ARNOVE, 1997; ARNOTT; RAAB, 2000; CLUNE; WITTE, 1990; WHITTY et al., 1998; WORLD BANK, 1995a; 1995b).

Entretanto, em que pese a tentativa de alguns analistas de associar a nova ortodoxia das reformas a um movimento amplo e homogêneo de caráter "neoliberal" ou neoconservador (APPLE, 2001; ARNOVE, 1997), o fato é que a promoção da "autonomia da escola" não encontra apoio apenas entre políticos da direita. De fato, há uma ambigüidade fundamental na administração baseada na escola (school-based management), na medida em que o discurso da "comunidade" que consubstancia tais propostas é suficientemente elástico para obter o apoio de grupos dos mais variados matizes ideológicos (WHITTY et al., 1998).

A ambigüidade ideológica desse modelo de empoderamento é menos surpreendente quando se consideram as raízes antiestatistas das críticas tanto da esquerda quanto da direita neoconservadora aos sistemas educacionais centralizados e administrados de forma burocrática (LAUGLO, 1995). Ao contrário de reformas mais polêmicas, como a introdução de mecanismos de escolha na educação (school choice), a submissão da escola ao controle da "comunidade" é uma proposta capaz de angariar amplo apoio, refletindo a força do discurso em torno da sociedade civil e de sua "libertação" das amarras estatais. O tema da sociedade civil está presente na retórica de defensores do capitalismo desregulado, tanto quanto dos adeptos do socialismo democrático e da social-democracia, de modo geral (BECKMAN, 1993).

O ponto a ser ressaltado por este artigo é que os defensores de formas colegiadas e democráticas de gestão escolar, independentemente das suas posições ideológicas, parecem concordar quanto à idéia de que as reformas promoverão o empoderamento dos pais e dos 
alunos, beneficiando sobretudo os grupos socialmente desfavorecidos. No Brasil, os pedagogos de esquerda viram na introdução de formas colegiadas e democráticas de gestão escolar a possibilidade de submeter a escola à "hegemonia" das classes trabalhadoras, desmantelando os padrões clientelistas e elitistas anteriormente vigentes (PRAIS, 1996; RODRIGUES, 1997).

Nos Estados Unidos, tanto grupos conservadores e tradicionalistas quanto a esquerda liberal argumentaram que o reforço da "autonomia da escola" daria mais "voz" a minorias étnicas e outros grupos marginalizados, contribuindo para a reversão de padrões prévios de segregação racial e de classes no interior do sistema educacional (CLUNE; WITTE, 1990; COOKSON, 1994; HESS, 1991). Na Inglaterra, Nova Zelândia e Austrália, os governos da Nova Direita defenderam que formas de gestão participativas e descentralizadas aumentariam a capacidade de pais e alunos intervirem nas políticas internas da escola, reduzindo a influência de professores e burocratas e suas práticas corporativistas (JACOBS, 2000; THOMAS, 1993; WHITTY et al., 1998).

Em que pesem as expectativas criadas em torno dessas propostas, o fato é que as evidências disponíveis para os casos citados mostram que, na prática, o efetivo empoderamento dos grupos desfavorecidos e sub-representados tem sido mais uma exceção do que a regra. Na visão dos críticos de esquerda das recentes reformas da governança educacional, há uma tensão inevitável entre a abordagem "gerencialista" e "economicista" hoje hegemônica e o discurso da "comunidade" e da "participação" que tornaria improvável a democratização efetiva da gestão escolar. Nessa perspectiva, o processo de descentralização ora em curso estaria sendo implementado de acordo com uma agenda neoconservadora ou "neoliberal" (no caso da América Latina), cujo real objetivo seria introduzir, em consonância aos modelos de gestão corporativos, novos e mais rígidos controles sobre os professores e administradores educacionais, muito mais do que promover o empowerment e a participação (MARTINS, 2001; WHITTY; POWER; HALPIN, 1998; RAAB, 2000; WATKINS, 1993). ${ }^{4}$ Se esta análise estiver correta, o sucesso das políticas de empoderamento dependeria da sua associação a agendas de esquerda genuinamente comprometidas com a radicalização da democracia e o combate às iniqüidades sociais.

Um segundo argumento, mais comumente aplicado ao Brasil e aos países da América Latina de modo geral, vem enfatizando as dificuldades da institucionalização de experiências participativas e de empoderamento em contextos marcados pela persistência de relações clientelistas e corporativistas e pela debilidade das instituições políticas representativas (JACOBI, 2000; MELO, 2003; MENDONÇA, 2000). De acordo com essa visão, a "fraqueza" da sociedade civil e a falta de instituições e práticas universalistas contribuiriam para dificultar o enraizamento das estruturas participativas e democráticas.

Com o intuito de avaliar os argumentos em torno das limitações das reformas descentralizadoras, foram selecionados alguns casos de reformas implementadas em três países: Brasil, EUA e Grã-Bretanha. Na escolha dos casos, buscou-se obter substancial variabilidade em termos do contexto social e político em que foram desenvolvidas as políticas de descentralização, bem como em termos da orientação ideológica dos grupos que defenderam tais políticas. Por meio da análise dos dados secundários disponíveis e da crítica aos argumentos presentes na literatura, busca-se desenvolver um raciocínio alternativo a respeito das "falhas" do empoderamento a ser apresentado na conclusão.

\section{REESTRUTURANDO A GESTÃO ESCOLAR NAGRÃ-BRETANHA}

Na Grã-Bretanha, os governos da Nova Direita defenderam a descentralização da gestão educacional em termos dos benefícios das soluções de mercado para a provisão de bens e serviços públicos. O primeiro governo Thatcher buscou tirar vantagem da atmosfera criada pela cobertura da mídia a respeito de supostas falhas e excessos cometidos por professores e administradores educacionais, particularmente no âmbito das autoridades educacionais locais - LEAs, controladas por administrações trabalhistas. Em tal contexto, a lei de educação de 1986 reformou os conselhos locais de administração educacional de modo a reverter a maioria de representantes das LEAs (até então garantida de forma institucional) e ampliar a participação de representantes dos pais e da comunidade de negócios. ${ }^{5}$

Mudanças mais radicais estavam para vir com a lei de educação de 1988, que transferiu poderes extensivos para os conselhos escolares e aumentou o poder de escolha dos pais e alunos (THOMAS, 1993). As reformas vieram acompanhadas por um movimento de recentralização, na medida em que o governo central aumentou seus poderes com o estabelecimento de padrões nacionais de currículo e mecanismos concentrados de avaliação (WHITTY et al., 1998, p. 20). A lei determinava que os conselhos escolares 
recebessem poderes deliberativos sobre vários assuntos, incluindo contratação de professores, currículo e disciplina (MUNN, 2000, p. 96). Os conselhos também ficaram responsáveis pela aprovação do orçamento da escola (LEVACIC, 1995). ${ }^{6}$

$\mathrm{Na}$ Inglaterra e no País de Gales, a lei determinava que os conselhos escolares tivessem representantes de pais e alunos da escola, professores e pessoas nomeadas pela LEA. Desde o início, os governos conservadores buscaram estimular a participação de pais provenientes do meio empresarial nos conselhos. Assim, dos cerca de 75 mil paisconselheiros nas escolas públicas da Inglaterra e do País de Gales, estima-se que aproximadamente $20 \%$ provenham do meio de negócios (WHITTY; POWER, 2003). Em complemento às estruturas colegiadas de gestão, foram introduzidos elementos de "escolha" e accountability de mercado. A "matrícula livre", isto é, a possibilidade de os pais escolherem a escola de seus filhos independentemente do local de residência, foi combinada com uma fórmula de financiamento baseada no número e na idade dos estudantes, forçando as escolas a competirem pela atração destes (LEVACIC, 1995; THOMAS, 1993).

Apesar do discurso em torno do empoderamento dos "usuários da escola", o fato é que os conselheiros leigos, isto é, representantes dos pais e alunos têm sido não mais que atores coadjuvantes na gestão dos conselhos. Uma revisão das várias pesquisas sobre o tema realizada por Munn (2000, p. 104) observou que muitos conselheiros se queixam da falta de conhecimento sobre os assuntos em discussão e da falta de tempo para se informar. Segundo Whitty e Power (2003, p. 797), mesmo quando os conselheiros leigos desejam se manifestar, sentem dificuldade para serem levados a sério ou mesmo para terem suas opiniões ouvidas. Pesquisas empíricas realizadas por Arnott e Raab (2000) e Levacic (1995) revelam ainda que a maior parte dos conselhos escolares depende bastante dos diretores e apenas aprovam, de forma passiva, os orçamentos preparados por estes.

Muitas análises sobre a "reestruturação da escola" na Grã-Bretanha parecem concordar que as reformas implementadas contribuíram para enfraquecer o profissionalismo pedagógico e introduzir novos mecanismos de controle administrativo e de mercado. Também tem se observado um movimento de recentralização do poder nas mãos do órgão principal de educação, o Departamento de Educação e Ciência, na esteira dos currículos e sistemas de avaliação centralizados (ARNOTT; RAAB, 2000; THOMAS, 1993; WHITTY et al., 1998).
De certo modo, o caso da Grã-Bretanha e de outros países de língua inglesa (WHITTY; POWER, 2003) parece confirmar os argumentos de esquerda sobre a existência de uma tensão irresoluta entre o tema da participação dos pais e uma abordagem individualista e mercantilista, orientada para a satisfação utilitária e para mecanismos de "saída", em oposição a mecanismos de "voz". Entretanto, como se verá adiante, a tentativa de atribuir a recente onda de reformas a uma agenda estritamente neoconservadora é problemática, mesmo naqueles casos em que não é possível falar, com absoluta certeza, da presença do seu oposto, isto é, de uma perspectiva de esquerda.

\section{EMPODERAMENTO A PARTIR DA "BASE"? A REFORMA DAS ESCOLAS DE CHICAGO}

Nos Estados Unidos, o debate sobre a reestruturação das escolas evoluiu especialmente por conta da crescente preocupação popular com o estado lastimável do sistema educacional americano, especialmente após a publicação do relatório nacional sobre educação pública Nation at Risk (Nação em Risco), em meados dos anos 80. Dado o sistema de governo federal e descentralizado do país, as respostas à crise da educação variaram bastante entre os Estados ou mesmo no interior destes. As políticas de descentralização e empoderamento têm envolvido o incremento da possibilidade de escolha dos pais (school choice), o reforço das normas de controle profissional e a atribuição de força à comunidade escolar por meio da introdução de conselhos escolares (COOKSON, 1994; FERNANDEZ, 1990; MOORE, 1990; MUNN, 2000).

Em contraste com a experiência da Grã-Bretanha, onde a reestruturação das escolas esteve claramente associada a uma agenda neoconservadora, nos EUA as políticas de descentralização e empoderamento contaram com o apoio de um vasto arco de forças políticas, envolvendo agendas e interesses variados. Comentando sobre a cruzada em favor da ampliação do poder de escolha dos pais e alunos, Cookson (1994) observou a formação de coalizões bastante heterogêneas, compreendendo educadores católicos e evangélicos, defensores de escolas "alternativas" e movimentos de defesa dos direitos civis. Na cidade de Chicago, uma experiência relativamente bem-sucedida de descentralização da gestão educacional foi apoiada por uma aliança singular envolvendo organizações de minorias negras e hispânicas, grupos de pais da classe média branca, liberais da velha guarda e neoconservadores adeptos da reestruturação radical das escolas (WHITTY et al., 1998, p. 33; HESS, 1991). 
A experiência de reforma em Chicago é digna de nota por duas razões. Primeiro por ter eclodido a partir da "base", com a pressão de grupos de pais de classe média e minorias étnicas insatisfeitos com o sistema educacional público. Segundo porque essa experiência, ao levar às últimas conseqüências uma visão radical sobre empoderamento, tornou-se modelo para outras reformas ao redor do mundo (WORLD BANK, 1995a).

A mobilização pública em favor da reestruturação das escolas de Chicago foi motivada pelo estado lamentável da rede educacional local: falta de verbas, segregação racial e altas taxas de evasão (HESS, 1991). Visando enfrentar esses problemas, as associações de moradores dos bairros da classe média branca se uniram às representações de pais de alunos negros e hispânicos, formando o movimento Chicago Unida pela Reforma da Educação - Cure. Posteriormente, o Cure obteria apoio de grupos de empresários com envolvimento em questões sociais. A aliança defendia um amplo programa de reforma calcado na transferência de amplos poderes decisórios - inclusive o poder de nomear o diretor - para conselhos escolares e a ampliação da capacidade de escolha das famílias (MOORE, 1990).

Após intenso processo de lobbying realizado pelo Cure, a Assembléia Legislativa do Estado de Illinois aprovou a lei de reforma em 1988, com o apoio de parlamentares dos partidos Republicano e Democrata. Os conselhos escolares obtiveram amplos poderes programáticos, orçamentários e de administração de pessoal. A lei estabelecia que os conselhos deveriam ser compostos majoritariamente por representantes dos pais (seis de um total de onze, incluindo o diretor). O novo órgão colegiado tinha o poder de definir o plano de melhoria da escola, aprovar o orçamento (com base nos recursos repassados em razão do número de alunos) e nomear diretamente o diretor da escola para um contrato de quatro anos, cuja renovação dependeria de análise de performance ulterior (HESS, 1991). Apesar dos amplos poderes dos diretores para contratar e demitir pessoal, todas as suas decisões importantes deveriam ser aprovadas no conselho (MOORE, 1990).

Diferentemente dos governos neoconservadores no Reino Unido, a preocupação dos reformadores em Chicago era garantir a inclusão racial e o apaziguamento dos conflitos, não introduzir controles administrativos e de mercado. ${ }^{7}$ Além disso, a reforma norte-americana refletiu sobretudo a expressão política de profundas divisões raciais e de classe no interior dos sistemas escolares, em vez de uma "resposta" consistente a tais conflitos articulada por elites partidárias e burocráticas.
Entretanto, em que pese a enorme capacidade de mobilização demonstrada pelas organizações da sociedade civil que apoiaram a descentralização do sistema educacional local, os resultados do "modelo de Chicago" parecem ter sido pouco animadores no que tange ao empoderamento dos pais e dos alunos. Uma pesquisa realizada a partir de uma amostra representativa das escolas de Chicago observou que o grande problema encontrado na implementação das reformas adveio do fato de que os pais e os alunos, na maioria dos casos, não acreditavam que poderiam participar de forma efetiva do processo de melhoria das suas escolas. Além disso, em $46 \%$ dos casos analisados, os conselhos tinham papel meramente simbólico, "carimbando" as decisões tomadas pelo diretor (HANDLER, 1996, p. 203). Embora a reforma tivesse como uma das suas metas a inclusão racial, os casos mais freqüentes de empoderamento foram encontrados entre pais brancos e de classe média (LEWIS; NAKAGAWA, 1995). Os mesmos autores argumentam que "a própria participação dos pais legitima a dominação dos profissionais sobre a formulação de políticas e a operação das escolas" (LEWIS; NAKAGAWA, 1995, p. 149).

A reforma de Chicago demonstra, em resumo, que mesmo no caso da construção do controle comunitário sobre a escola a partir da organização e mobilização da sociedade civil, não há garantia de obtenção dos resultados esperados no que diz respeito ao empoderamento. De forma sintomática, como observado por Whitty e Power (2003, p. 802), as reformas subseqüentes em Chicago afastaram-se bastante do controle comunitário e substituíram os conselhos escolares por formas de intervenção política e profissional mais convencionais, na medida em que o departamento de educação local recuperou parte das suas atribuições em 1995.

O que se pode inferir, com base nas análises citadas, é que a luta pelo empoderamento e pela descentralização encontra a resistência de estruturas de poder consolidadas no interior das escolas e da burocracia educacional, independentemente da ideologia dos grupos pró e contra as reformas. Assim, a crítica da esquerda que considera o "seqüestro" da agenda do empoderamento pelo racionalismo econômico neoconservador como o principal calcanhar-de-aquiles dessas políticas pode estar deixando de lado uma parte importante do problema. Na seção seguinte, esse ponto é desenvolvido de forma mais detalhada a partir da análise de algumas reformas da gestão educacional implementadas no Brasil, completando o elenco de comparações deste trabalho. 


\section{“DEMOCRATIZANDO" A ESCOLA: A EXPERIÊNCIA BRASILEIRA}

No caso do Brasil, como já observado, a luta pela descentralização da administração educacional e pelo empoderamento da comunidade escolar se confundiu, ao menos no início, com o processo de redemocratização do país e com a crítica ao Estado autoritário e seu modelo de gestão das políticas sociais. Assim como nos EUA, a existência de um sistema federal em que Estados e municípios detêm poder significativo sobre a administração das suas redes educacionais favoreceu a fragmentação das políticas descentralizadoras. Ademais, de meados dos anos 80 até o início do governo Fernando Henrique Cardoso (1994-02), o governo federal não se empenhou de forma consistente na promoção de formas descentralizadas de gestão estadual e municipal ou no repasse de recursos e atribuições para as demais unidades federadas (ALMEIDA, 1995). Assim, a introdução de formas inovadoras de administração dependeu, a princípio, dos governos estaduais e municipais, variando muito em termos de natureza, ritmo e intensidade. ${ }^{8}$

Entre as inovações institucionais no campo da educação se destacam os conselhos escolares com representantes dos professores, pais e estudantes e a eleição direta dos diretores de escola. Desde meados dos anos 80, alguns Estados vêm transferindo recursos diretamente para a escola, conferindo aos conselhos escolares o poder de preparar e aprovar os orçamentos, com o apoio do diretor (BARROS; MENDONÇA, 1998; PARENTE; LUCK, 1999). ${ }^{9}$ Por sua vez, a seleção de diretores via eleição direta, implantada em diversos Estados e municípios, marca a especificidade da experiência brasileira de descentralização, fortemente associada à luta contra o regime autoritário e suas políticas de controle ideológico da escola (CUNHA, 1991; PARO, 1996).

Buscando capturar a variedade das experiências de empoderamento e descentralização desenvolvidas pelos Estados e municípios, esta seção analisa duas experiências de reforma que podem ser consideradas representativas de visões polares sobre o processo educacional e sua articulação com a economia de mercado. De um lado, no Município de São Paulo, a administração do Partido dos Trabalhadores - PT adotou um programa de descentralização calcado na "pedagogia da libertação" defendida pelo educador Paulo Freire, então nomeado secretário da educação. De outro, no Estado de Minas Gerais, a introdução de formas colegiadas e "democráticas" de ges- tão escolar foi apoiada por consultores e formuladores de políticas ligados ao Banco Mundial e ao BID, adeptos dos modelos gerencialistas e de quase-mercado defendidos por estas instituições.

Na cidade de São Paulo, a introdução de mecanismos de empoderamento nas escolas ocorreu durante a administração do secretário Paulo Freire, no período 1989-91. Conhecido internacionalmente por seu trabalho sobre educação popular, Freire estabeleceu como medida prioritária a democratização da gestão escolar. Seguindo sua própria produção teórica, o secretário buscou associar a política educacional a um projeto histórico de emancipação social (FREIRE, 1972; O’CADIZ et al., 1998, p. 50). Tal agenda era condizente com o programa de governo da prefeita Luíza Erundina, estruturado para promover a formação de conselhos populares autônomos e a "inversão de prioridades", reorientando os investimentos públicos de modo a atender às necessidades e aos direitos sociais dos setores mais carentes da população (JACOBI, 2000, p. 22).

Em contraste com outras experiências contemporâneas de reestruturação da gestão educacional, a proposta do PT em São Paulo objetivava a descentralização radical do planejamento curricular. Os professores, juntamente com os alunos, passavam a ter a possibilidade de desenvolver seus próprios planos curriculares, de acordo com os princípios teóricos desenvolvidos pelo secretário-educador Paulo Freire. Com tal processo, buscava-se também repensar a relação educador-educando, tornando os alunos sujeitos, não mais objetos, do processo de ensino (O'CADIZ et al., 1998, p. 236).

Além da descentralização do currículo, as políticas de empoderamento adotadas no setor educacional envolveram a transferência de poder decisório sobre orçamentos e alguns aspectos de administração de pessoal para conselhos escolares representativos. Os conselhos eram compostos de professores, funcionários da escola e alunos. Para cada 40 conselhos de escola foram eleitos delegados que tinham assento nos conselhos dos departamentos regionais de educação, então denominados Núcleos de Ação Educativa - NAEs (O’CADIZ, et al., 1998, p. 53). A estrutura colegiada e participativa dos NAEs visava aproximar a população do corpo diretivo da secretaria, quebrando a lógica autoritária e hierárquica da burocracia educacional. A idéia da administração petista era criar um novo movimento social no interior das escolas, de modo a garantir apoio às políticas implementadas (O’CADIZ, et al., 1998, p. 82).

Entretanto, em que pese o desejo da administração Paulo Freire de empoderar a sociedade civil, em particular os seus 
segmentos mais desfavorecidos, os resultados das reformas implementadas em São Paulo ficaram muito aquém do desejado. Na prática, a proposta dos NAEs e dos conselhos de escola enfrentou a oposição dos professores e administradores educacionais, que resistiam à divisão do poder propiciada pelas estruturas colegiadas (JACOBI, 2000, p. 23). A lógica hierárquica e centralizada da rede de ensino, somada ao corporativismo do funcionalismo público municipal, contribuiu para dificultar enormemente a implementação das políticas de empoderamento. De forma sintomática, uma das mais importantes propostas da administração Paulo Freire relativas à democratização da gestão educacional - a eleição direta dos diretores e vice-diretores de escola - foi derrubada por sindicalistas, professores e diretores que se opunham a tal processo, temendo a perda de vários direitos trabalhistas gozados pelos diretores. Devido à pressão eficiente destes grupos, o novo estatuto do magistério proposto pela secretaria foi derrotado na Câmara Municipal, com o apoio dos vereadores que temiam perder o direito de nomear os diretores de escola (O'CADIZ et al., 1998, p. 82).

Em muitos casos, os NAEs e os conselhos de escola ficaram sujeitos à manipulação por parte dos professores e outros funcionários das escolas, dificultando a participação autônoma dos pais. Apenas nas regiões em que havia maior mobilização foi possível obter melhores resultados em termos da integração da proposta participativa (JACOBI, 2000, p. 23). O programa de descentralização do planejamento curricular, apesar de ter sido bem-sucedido em alguns casos, também não logrou se institucionalizar, enfrentando sérias resistências por parte dos professores. A baixa institucionalização das propostas de reforma pode ser observada tendo em vista a facilidade com que a nova administração, eleita em 1990, desarticulou as formas de participação inovadoras, introduzindo em seu lugar um programa de gestão educacional baseado nos princípios do controle de qualidade total (O'CADIZ et al., 1998; JACOBI, 2000, p. 24).

O caso da reforma educacional em São Paulo coloca em questionamento, de forma bastante clara, os argumentos em torno dos limites do empowerment apresentados pelos críticos de esquerda. Isto é, mesmo quando implementadas por governos de orientação socialista ou social-democrata, as políticas de empoderamento da comunidade escolar enfrentam dificuldades concretas, associadas à resistência dos vários atores que detêm o poder de fato sobre a escola: professores, políticos e burocratas. Ironicamente, os maiores opositores das propostas de reforma da admi- nistração petista de Luíza Erundina não eram os partidos políticos conservadores, minoritários na Câmara Municipal, mas os professores e sua representação sindical, os quais têm constituído, via de regra, importante base eleitoral do PT e demais partidos de esquerda no Brasil.

$O$ último caso de reforma educacional analisado neste artigo ocorreu em Minas Gerais, a partir de 1991. A reforma mineira envolveu o fortalecimento dos conselhos de escola, com o aumento de seus poderes administrativos e financeiros. A Secretaria da Educação do Estado instituiu fundos vinculados e não-vinculados a serem transferidos diretamente às escolas e gerenciados pelos conselhos escolares (GUEDES et al., 1997; GUIA NETO, 1994).

Em Minas Gerais, o processo de descentralização da gestão educacional contou com o crucial apoio técnico e financeiro de agências internacionais e consultores ligados a essas instituições, refletindo uma perspectiva que enfatiza os impactos do investimento educacional sobre o crescimento econômico e a redução de custos propiciada pela descentralização, muito mais do que outros aspectos, relativos à ampliação da participação popular. A reestruturação do sistema de ensino visava torná-lo mais acessível, eficiente e menos oneroso, criando incentivos para a melhoria da qualidade das escolas (GUIA NETO, 1994; OLIVEIRA, 2000).

Apesar da ênfase em aspectos de aumento da eficiência e redução de custos, a reforma mineira logrou responder a uma das principais demandas dos sindicatos de professores e movimentos sociais ligados à educação, instituindo a eleição direta de diretores de escola. Desde meados dos anos 80 , a principal entidade sindical dos professores e demais trabalhadores da educação do Estado, o Sindicato Único dos Trabalhadores da Educação - SindiUTE, havia colocado em sua pauta de reivindicações a introdução de eleições nas escolas, recorrendo a paralisações e greves como forma de pressão sobre os governadores eleitos. No entanto, embora as lideranças sindicais defendessem a eleição de diretores como forma de "democratizar" a escola, a representação do professorado tinha como objetivo primordial acabar com a prática de nomeação de diretores afinados com o partido no poder e invariavelmente hostis às mobilizações grevistas. Era esperado que diretores eleitos e, portanto, dependentes dos votos da categoria, acabassem por ser mais simpáticos aos sindicatos, ampliando a capacidade de mobilização destes (BORGES, 2004). ${ }^{10}$

Se é verdade que as representações sindicais dos professores mineiros não se colocaram explicitamente contra a participação de pais e alunos no processo eleitoral, o fato 
é que havia o temor, sobretudo da parte do governo estadual, de que a instituição das eleições acabaria por deixar as escolas "nas mãos" dos sindicatos e dos partidos de esquerda associados a estes últimos, em particular o PT (ROCHA, 2000). De forma sintomática, a partir da terceira eleição de diretores realizada em Minas Gerais, no ano de 1996 (as duas primeiras ocorreram em 1991 e 1993), retirouse o critério de proporcionalidade dos votos, instituindose o voto universal (até então professores e funcionários tinham $50 \%$ dos votos, ao passo que pais e alunos, outros $50 \%$ ). O objetivo era claramente aumentar o peso dos votos dos pais e dos alunos no processo eleitoral, reduzindo a possibilidade de manipulação por professores e funcionários (BORGES, 2004).

Embora não existam dados sistemáticos sobre o impacto desta última medida, parece haver evidência de que os professores e funcionários têm tido influência significativa na política interna das escolas. Pesquisa realizada por Guedes et al. (1997) em algumas escolas mineiras observou que muitas comunidades escolares demonstram "falta de amadurecimento político", no sentido de que boa parte dos pais e estudantes não participa do processo eleitoral. Assim, os diretores acabam sendo eleitos pelos professores e funcionários, tornando-se mais sensíveis às pressões deste último grupo. Se a amostra de escolas recolhidas na pesquisa não é representativa, as evidências são compatíveis com o observado em outras unidades da Federação. As pesquisas sobre o tema mostram que os diretores eleitos muitas vezes se tornam "reféns" dos professores e funcionários, adotando medidas que visam agradar o seu "eleitorado", como, por exemplo, relaxando no controle das faltas dos professores (VIEIRA et al., 1996; PARO, 1996). ${ }^{11}$

No que tange aos conselhos escolares, a experiência de Minas Gerais também traz evidências de que os professores e a direção da escola tendem a dominar as novas estruturas de gestão. Guedes et al. (1997) observaram que muitos conselhos atuam de forma simbólica, apenas aprovando passivamente as decisões do diretor. Também foi verificado que, em alguns casos, os professores e os diretores intimidam os alunos a votarem "com eles", valendo-se do seu poder disciplinar. Em outras instâncias, os professores e os diretores buscam garantir a maioria dos votos antes de agendar uma reunião de conselho, tornando irrelevante a ação dos seus opositores. Pesquisa empírica realizada por Mattos (1998) em algumas escolas de ensino fundamental observou ainda que os membros mais ativos do colegiado são os professores mais politizados, alguns inclusive com experiência em atividade sindical.
Algumas lições importantes podem ser extraídas da experiência de empowerment da comunidade escolar em Minas Gerais e São Paulo. O primeiro ponto a ser ressaltado diz respeito ao papel crucial desempenhado por administradores educacionais, professores e seus sindicatos no sentido de manter ou transformar as estruturas de gestão da escola. A experiência de São Paulo, em particular, contrasta fortemente com o caso de Chicago, onde a descentralização foi defendida por uma ampla rede de organizações de pais e estudantes de origens étnicas e de classes variadas. Em São Paulo, os pais e os estudantes eram não mais que atores coadjuvantes em uma arena decisória onde predominavam as agendas e os interesses, nem sempre convergentes, da administração municipal do Partido dos Trabalhadores, de um lado, e dos professores e administradores educacionais, do outro. Em Minas Gerais, em que pese a existência de uma associação representativa dos pais e estudantes - a Federação das Associações dos Pais e Mestres, FapaeMG - esta última era uma organização frágil, restrita quase exclusivamente à cidade de Belo Horizonte e arredores, cujo poder de pressão nem de longe se igualava ao dos sindicatos (BORGES, 2004; ROCHA, 2000).

Em outras palavras, ambos os casos sugerem que a política de descentralização reflete uma disputa pelo poder sobre as escolas e o processo educacional, na qual os grupos que se espera "empoderar" - pais e estudantes desempenham papel apenas secundário. Tal inferência não corrobora, no entanto, a tese de que o fracasso das experiências participativas na educação pode ser creditado apenas ao baixo nível de organização da sociedade civil. Mesmo no caso de Chicago, onde as políticas de empoderamento se seguiram à mobilização de uma densa rede de organizações de minorias étnicas e associações de bairro, os resultados das novas estruturas descentralizadas revelaram-se decepcionantes $v i s-\grave{a}$-vis as expectativas. Isso leva a atentar para o segundo nível das políticas de descentralização, isto é, o nível da escola, onde ocorre a implementação dos novos procedimentos decisórios. No âmbito da micropolítica educacional, a cultura hierárquica e autoritária que permeia as relações entre professores, administradores, pais e alunos limita seriamente as tentativas de se promover a efetiva democratização da gestão escolar.

\section{CONSIDERAÇÕES FINAIS}

De modo geral, o discurso em torno das reformas que visam descentralizar e democratizar a gestão educacional tem sido marcado por um forte viés anti-Estado e antibu- 
rocracia, refletindo um amplo consenso em torno das virtudes do empowerment da sociedade civil. Entretanto, mesmo nas suas versões "radical-democráticas" e de esquerda tais reformas vêm enfrentando a dura realidade da disputa pelo controle da escola e do processo educacional entre vários atores intra-estatais - administradores, professores e políticos eleitos. Assim, se há um “defeito de origem" nas políticas de empoderamento para a educação, como sugerido pela crítica de esquerda, este não se encontra na visão gerencialista e economicista de muitos dos seus proponentes, mas no fato mais corriqueiro de que tais políticas enfrentam arranjos de poder bastante cristalizados e não passíveis de enfrentamento por meio apenas da criação de estruturas decisórias colegiadas e representativas. Em resumo, a crítica radical às reformas "neoliberais" e neoconservadoras da gestão educacional tende a ignorar aspectos que escapam à dicotomia direita-esquerda, estando portanto sujeita a sérios questionamentos.

Outro argumento sobre os limites do empoderamento aplicado ao Brasil tem enfatizado a debilidade das instituições políticas representativas, a persistência de práticas clientelistas e a fraqueza das organizações da sociedade civil como fatores responsáveis pela dificuldade de institucionalização de práticas genuinamente participativas e democráticas. Se esse argumento encontra alguma confirmação empírica no caso brasileiro, a experiência de Chicago mostra que mesmo reformas realizadas a partir da mobilização da sociedade civil enfrentam dificuldades significativas para promover o efetivo empoderamento da comunidade escolar. É preciso levar em conta a especificidade das burocracias educacionais e suas estruturas internas de poder, calcadas numa lógica de disciplina e autoridade bastante arraigada. As pedagogias libertadoras pelo menos têm reconhecido o problema, vendo na mudança dos padrões hierárquicos característicos da relação professor-aluno o eixo fundamental da reestruturação da escola. O caso da reforma paulista mostra, no entanto, as enormes dificuldades de se colocar em prática tais propostas.

Apesar do tom um tanto pessimista da conclusão deste artigo, o que se quer é compreender os limites das políticas de empowerment na educação, e não rejeitá-las de todo. Dessa forma, busca-se repensar a agenda que tem dominado as reformas contemporâneas da gestão educacional, atentando para os seus vieses e problemas de implementação.

Como observado por Handler (1996), a idéia de empowerment embute uma contradição fundamental, ao prescrever um processo democrático e igualitário entre participantes desiguais em termos de poder e recursos. Em outros termos, se a realização plena da democracia requer um certo nivelamento das diferenças sociais e de status, como já observado por pensadores como Tocqueville e Aristóteles, o problema não pode jamais se resumir à criação de estruturas colegiadas e formalmente democráticas. Mesmo numa situação ideal em que tais estruturas fossem capazes de "empoderar" pais e alunos de maneira uniforme no interior do sistema educacional, ainda assim seria de se esperar que os indivíduos de maior renda e escolaridade acabassem por ter mais "voz" no processo participativo. ${ }^{12}$ A questão se torna ainda mais premente em sociedades como a brasileira, marcadas por profundas desigualdades sociais.

Um dos aspectos que cumpre observar, nesse sentido, é até que ponto a perspectiva antiestatista que tem dominado o debate intelectual em torno das reformas contemporâneas da gestão educacional não tem contribuído para cegar os acadêmicos e formuladores de políticas quanto à importância do papel de políticas de Estado centralizadas e uniformes no sentido da correção das desigualdades sociais e inclusão de grupos marginalizados. O desafio que se coloca, portanto, é como lidar com a tensão entre políticas descentralizadoras, com potencial para reproduzir e reforçar as desigualdades e a fragmentação social, e a criação de novos espaços comunitários a partir de políticas públicas de minimização das desigualdades desenvolvidas na linha dos programas universalistas e centralizados do Welfare State. Enfrentar tal dilema é certamente a tarefa fundamental a que se devem dedicar todos aqueles que acreditam na possibilidade da criação de espaços solidários, democráticos e de resistência ao racionalismo econômico de velhos e novos apologistas dos mercados desregulados.

\section{NOTAS}

1. Whitty e Power (2000) argumentam, no entanto, que o efeito dessas reformas costuma ser exatamente o contrário do esperado, na medida em que as escolas de melhor performance selecionam intencionalmente os melhores estudantes, os quais provêm, quase sempre, das famílias de maior renda e escolaridade. Assim, os argumentos em torno dos modelos de school choice são baseados mais na preferência ideológica por mecanismos de mercado do que na comprovação empírica dos benefícios esperados.

2. Apesar do uso indiscriminado do conceito de "autonomia da escola" para descrever tais reformas, a aplicação do termo é problemática, já que em muitos casos o que se processou foi uma redução da autonomia no que tange a aspectos cruciais no processo de ensino, quais sejam, a definição dos currículos e a avaliação do processo de ensino-aprendizagem, que passaram a ser impostos de forma centralizada para o conjunto das escolas. 
3. O caráter conservador das reformas educacionais implementadas em países como Inglaterra, Nova Zelândia e Austrália revelase na tentativa de restaurar os valores tradicionais e reintroduzir a disciplina e a ordem nas escolas, envolvendo um ataque frontal à "ortodoxia progressista" no interior do sistema educacional (APPLE, 2001). No caso da Nova Zelândia, por exemplo, os reformadores buscaram criar um clima de histeria na opinião pública, apresentando os sindicatos "feministas" e a burocracia educacional como grupos inimigos dos valores morais "corretos", que teriam "capturado" o processo educativo para seu próprio benefício (JACOBS, 2000).

4. O termo "neoliberalismo" tem sido utilizado de forma imprecisa nas ciências sociais, conotando uma ampla e heterogênea gama de fenômenos: desde a "americanização" cultural até agendas de políticas públicas que seriam melhor caracterizadas como neoconservadoras. No texto, o conceito é utilizado de forma mais restrita, em referência às formas contemporâneas assumidas pelo liberalismo econômico clássico. Embora, em muitos casos, a defesa do "novo" liberalismo tenha vindo associada à agenda da direita conservadora, a rigor existem diferenças importantes entre as posições liberais e conservadoras "puras". Por conta disso, é necessário cuidado no uso do termo.

5. As autoridades educacionais locais seriam equivalentes às secretarias municipais da educação no Brasil, embora as primeiras nem de longe detenham a autonomia destas últimas. Como é comum em muitos países unitários, na Grã-Bretanha a gestão do sistema educacional é fundamentalmente de competência do governo central. Assim, as LEAs não possuíam o poder de formular políticas próprias como têm as secretarias municipais de educação no Brasil.

6. É interessante observar que na Escócia as mudanças foram menos radicais do que na Inglaterra e no País de Gales. A lei escocesa de educação de 1988, que se seguiu à lei nacional aprovada no parlamento em Londres, transferia poucos poderes para os conselhos e preservava bastante a autonomia profissional dos professores, diminuindo o papel efetivo dos conselhos e dos diretores de escola (MUNN, 2000, p. 96).

7. Não por acaso, a reforma de Chicago recebeu críticas tanto da direita neoconservadora quanto da esquerda liberal, dada a falta de coerência ideológica da aliança pró-reforma. Em defesa do modelo de Chicago, no entanto, Hess (1994) ponderou que as suas raízes intelectuais estavam claramente na abordagem igualitária da perspectiva liberal tradicional, com a diferença da rejeição da abordagem centralizada defendida pelos "antigos" liberais.

8. Desde 1994 tem havido uma maior preocupação do governo federal no sentido de harmonizar a política educacional das três esferas de governo e induzir a adoção, pelos Estados e municípios, de formas participativas de gestão escolar - e.g., conselhos de escola (CASTRO et al., 2000). No entanto, deve-se ressaltar que, a capacidade do governo federal de produzir políticas homogêneas no setor educacional é provavelmente limitada comparativamente a outros países da América Latina, dada a existência de redes educacionais relativamente autônomas em lugar de um sistema único e nacional de educação. Assim, se é verdade que o modelo de gestão das políticas educacionais defendido pelo Banco Mundial e pelo BID foi claramente o vencedor dos embates político-ideológicos no plano nacional ao longo dos anos 90 (TOMMASI et al., 1998), isso não impediu que governos municipais ou estaduais de esquerda ou centro-esquerda implementassem políticas e reformas da educação não necessariamente condizentes com o pregado pelo governo federal.

9. Essas experiências foram posteriormente aproveitadas pelo programa federal Dinheiro Direto na Escola, que envolve a transferência de fundos para escolas municipais e federais, condicionada à criação de conselhos escolares (CASTRO et al., 2000).

10. Essa não era uma peculiaridade da representação sindical dos professores mineiros, vale dizer, mas reflete o caráter corporativista que a luta pela eleição de diretores assumiu, em muitos casos.
Uma das experiências pioneiras de eleição de diretores no país, realizada em 1984 no município de Volta Redonda (RJ), por exemplo, conferia o direito de voto apenas aos professores e funcionários da escola. Naquele momento, a seção municipal do Sindicato dos Professores do Estado do Rio de Janeiro se colocou contra a participação de pais e alunos, vendo a eleição apenas como uma forma de assegurar um bom relacionamento entre a categoria e os diretores (OLIVEIRA, 1998, p. 29).

11. Em que pesem suas limitações como instrumento de empowerment, no entanto, a eleição de diretores tem representado um avanço considerável, por colocar fim às interferências políticas que marcavam o sistema de nomeação do diretor pelas secretarias estaduais e municipais de educação. Além disso, parece haver evidências de que os diretores eleitos demonstram maior preocupação em prestar contas à comunidade escolar e realizar uma boa gestão.

12. De fato, várias pesquisas sobre empoderamento nos países desenvolvidos de língua inglesa mostram o caráter elitista das novas estruturas participativas, na medida em que os pais de classe média e alta costumam ser mais bem-sucedidos na defesa dos seus interesses. Para uma revisão desta literatura ver, Whitty; Power (2000; 2003).

\section{REFERÊNCIAS BIBLIOGRÁFICAS}

ALMEIDA, M.H.T. Federalismo e Políticas Sociais. Revista Brasileira de Ciências Sociais, n. 28, p. 88-108, 1995.

APPLE, M. Comparing Neo-Liberal Projects and Inequality in Education. Comparative Education, 37, 4, p. 409-423, 2001.

ARNOTT, M.; RAAB, C. (Ed.). The governance of schooling: Comparative studies of devolved management. London; New York: Routledge, 2000.

ARNOVE, R.F. Neoliberal Education Policies in Latin American. In: TORRES, C.A.; PUIGRÓS, A. (Ed.). Latin American Education: Comparative Perspectives. Boulder: Westview Press, 1997.

BARROS, R. de.; MENDONÇA, R. Impacto de três inovações institucionais na educação brasileira. Rio de Janeiro, Ipea, 1998. (Texto para discussão).

BECKMANN, B. The Liberation of Civil Society: Neo-Liberal Ideology and Political Theory. Review of African Political Economy, 58, p. 20-33, 1993.

BORGES, A. Bottom-up Pressures and Elite Strategies: Institutionalising School-Level Elections in Minas Gerais. Oxford: University of Oxford, 2004. Mimeografado.

CASTRO, J.A. de et al. A reestruturação das políticas federais para o ensino fundamental: descentralização e novos mecanismos de gestão. Rio de Janeiro, Ipea, 2000. (Texto para discussão).

CHUBB, J.E.; MOE, T.M. Politics, Markets and the Organization of Schools. American Political Science Review, v. 82, n. 4, p. 1061-1087, 1988.

CLUNE, W.H.; WITTE, J. F. (Ed.). Choice and control in American education. London: The Falmer Press, 1990.

COOKSON, P.W. School choice: the struggle for the soul of American education. New Haven; London: Yale University Press, 1994.

CUNHA, L.A.F. Educação, Estado e Democracia no Brasil. São Paulo: Cortez, 1991. 
FERNANDEZ, J.A. Dade County Public Schools Blue Print for Restructured Schools. In: CLUNE, W.; WITTE, J. (Ed.). Choice and control in American education. London: The Falmer Press, v. 2, 1990.

FISCHMAN, G.E.; MCLAREN, P. Schooling for democracy: towards a critical utopianism. Contemporary Sociology, v. 29, n. 1 , p. $168-179,2000$.

FREIRE, P. Pedagogy of the oppressed. Harmondsworth: Penguin Education, 1972.

FRIEDMAN, M.; FRIEDMAN, R.D. Capitalism and freedom. Chicago: University of Chicago Press, 1962.

GANDIM, L.A.; APPLE, M. Challlenging neo-liberalism, building democracy: creating the Citizen School in Porto Alegre. Journal of Education Policy, v. 17, n. 2, p. 250-279, 2002.

GUEDES, A. et al. Gestion decentralizada de la educación em el Estado de Minas Gerais, Brasil. Policy Evaluation Paper. Human Development Group. Washington D.C.: World Bank, 1997.

GUIA NETO, W.M. Educação e desenvolvimento: conscientização, vontade política e participação. Estudos em Avaliação Educional, n. 9, p. 9-16, jan./jul.1994.

HANDLER, J.F. Down from bureaucracy: the ambiguity of privatization and empowerment. Princeton: Princeton University Press, 1996.

HESS, G.A. Race and the Liberal Perspective in Chicago School Reform. In: MARSHALL, C. (Ed.). The New Politics of Race and Gender. Washington D.C.: The Falmer Press, 1994.

School restructuring, Chicago style. Newbury Park: Corwin, 1991.

JACOBI, P.R. Educação, ampliação da cidadania e participação. Educação e Pesquisa, v. 26, n. 2, p. 11-29, 2000.

JACOBS, K. Devolved management in New Zealand schools. In: ARNOTT, M.; RAAB, C. (Ed.). The governance of schooling: Comparative studies of devolved management. London; New York: Routledge, 2000.

LAUGLO, J. Forms of decentralisation and their implications for education. Comparative Education, v. 31, p. 1-38, 1995.

LEVACIC, R. Local Management of schools: analysis and practice. Buckingham; Philadelphia: Open University Press, 1995.

LEWIS, D.A.; NAGAKAWA, K. Race and educational reform in the American metropolis: a study of school decentralization. Albany: Suny, 1995.

MARTINS, A.M. A descentralização como eixo das reformas do ensino: uma discussão da literatura. Educação e Sociedade, v. 22, n. 77, p. 28-48, 2001.

MATTOS, L.A.F. Democracia e colegiado da escola: qual democracia? Um estudo da gestão colegiada em Minas Gerais. Tese (Doutorado em Educação) - Faculdade de Educação, UFRJ, Rio de Janeiro, 1998.

MELO, M.A. Empowerment e governança no Brasil: questões conceituais e análise preliminar de experiências selecionadas. Brasília: World Bank, Brazilian Office, 2003. Mimeografado.

MENDONÇA, E.F. Estado patrimonial e gestão democrática do ensino público no Brasil. Educação e Sociedade, v. 22, n. 75, p. 84-108, 2001.

MOORE, D. Voice and choice in Chicago. In: CLUNE, W.; WITTE, J. (Ed.). Choice and control in American education. London: The Falmer Press, v. 2, 1990.

MUNN, P. School boards and governing bodies: A vehicle for parental participation in decision-making about schools? In:
ARNOTT, M.; RAAB, C. (Ed.). The governance of schooling: Comparative studies of devolved management. London; New York: Routledge, 2000.

O'CADIZ, M.P. et al. Education and democracy: Paulo Freire, social movements, and educational reform in São Paulo. Boulder: Westview, 1998.

OLIVEIRA, A. A eleição de diretores e a gestão democrática da escola pública. São Paulo: Editora Alfa-Omega, 1998.

OLIVEIRA, D.A. Educação básica: Gestão do trabalho e da pobreza. Petropólis: Vozes, 2000.

PARENTE, M. de A.; LUCK, H. Mapeamento da descentralização da educação brasileira nas redes estaduais do ensino fundamental. Rio de Janeiro: Ipea, 1999. (Texto para discussão).

PARO, V. Eleição de diretores: a escola pública experimenta a democracia. Campinas: Papirus, 1996.

PRAIS, M. Administração colegiada na escola pública. Campinas: Papirus, 1996.

RAAB, C. Restructuring the governance of schools in Scotland and England. In: ARNOTT, M.; RAAB, C. (Ed.). The governance of schooling: Comparative studies of devolved management. London; New York: Routledge, 2000.

ROCHA, C. A descentralização político-administrativa do ensino público em Minas Gerais: um caso de mudança institucional. Tese (Doutorado) - Unicamp, Campinas, 2000.

RODRIGUES, N. Por uma nova escola: o transitório e o permanente na educação. São Paulo: Cortez, 1997.

SAMOFF, J. Decentralization: the politics of interventionism. Development and Change, v. 21, p. 513-530, 1990.

SUNDAR, N. Is devolution democratization? World Development, v. 29, n. 12, p. 2007-2023, 2001.

THOMAS, H. The education reform movement in England and Wales. In: HEDLEY, H.; LOWE, B. (Ed.). Restructuring schools. Washington; London: The Falmer Press, 1993.

TOMMASI, L. de. et al. (Org.). O Banco Mundial e as políticas educacionais. São Paulo: Cortez, 1998.

VIEIRA, S.V. et al. Eleição de diretores, o que mudou na escola? Brasília: Plano Ed., 1996.

WATKINS, P. Pushing crisis ans stress down the self-managing school. In: SMYTH, J. (Ed.). A socially critical view of the selfmanaging school. London: The Falmer Press, 1993.

WHITTY, G.; POWER, S. Mercados educacionais e a comunidade. Educação e Sociedade, v. 24, n. 84, p. 719-815, 2003.

Marketization and privatization in mass education systems. International Journal of Educational Development, v. 20, n. 1, p. 93-107, 2000.

WHITTY, G. et al. Devolution and choice in education: the school, the state and the market. Buckingham: Open University Press, 1998.

WORLD BANK. Priorities and Strategies for Education: A World Bank Review. Washington, D.C.: World Bank, 1995a.

Private and public initiatives - Working Together for Health and Education. Washington, D.C.: World Bank, 1995b.

André Borges:. Doutorando em Ciência Politica na Universidade de Oxford (andre.carvalho@sant.ox.ac.uk). 